\title{
João do Rio e os gêneros jornalísticos no início do século xx
}

\begin{abstract}
RESUMO
A obra de João do Rio constitui um objeto indispensável para a reflexão acerca do desenvolvimento dos gêneros jornalísticos no Brasil. Passadas décadas no esquecimento, sua revalorização necessita, todavia, de alguns ajustes. Fundamentalmente: é necessário situá-la com rigor em um contexto particular, o do início do século XX, momento em que o jornalismo no país passava por uma significativa transformação, com o abandono de sua feição doutrinária e a incorporação de uma dinâmica comercial e empresarial. O reconhecimento das peculiaridades desse contexto é chave imprescindível para se compreender como se configuram os gêneros jornalísticos presentes em suas principais obras. Com isso, dimensiona-se o caráter plural na conformação de gêneros provenientes do jornalismo europeu que se manifesta, por exemplo, na simbiose entre reportagem e crônica.
\end{abstract}

\section{PALAVRAS-CHAVE}

- gêneros jornalísticos

- reportagem

- história da imprensa

\section{ABSTRACT}

João do Rio's work is an indispensable object for the reflection about the development of journalist genres in Brazil. After decades of negligence the revalorization of this work needs some adjustments, though. Basically, it is necessary to strictly locate Rio's work in a very specific context: the beginning of the 20th century - moment in which journalism in the country was suffering significant changes, the interruption of its political engagement and the incorporation of a commercial and business-like dynamic. The recognition of the peculiarities of this context is the key for understanding how the journalist genres presented in Rio's main work are formed. By this analysis the plural characteristic in the configuration of genres originated from the European journalism, as the symbiosis between news reporting and chronicle, can be measured.

\section{KEY WORDS}

- journalistic genres

- news reporting

- press history

\section{Marcelo Bulhões UNESP}

0 nome de João do Rio ficou décadas no esquecimento. Há algum tempo vem sendo "resgatado" e revalorizado, com alguma euforia. Livros e artigos têm destacado sua importância para a cultura brasileira, para a história de nossa imprensa jornalística, situando-o como o "cronista da nossa Belle Époque", iniciador do jornalismo investigativo no país e até reconhecendo, tacitamente, que sua obra não deveria ficar de fora do cânone da própria literatura brasileira. Penso, todavia, que tal "reabilitação" e o reconhecimento tardio de sua importância merecem maior cuidado de apreciação e, às vezes, alguns ajustes e retificações. É tentador afirmar - como se tem feito - que ele foi o inovador da imprensa jornalística brasileira por misturar dois gêneros, reportagem e crônica, o que resultaria em um novo gênero, misto. Identifico aí um equívoco, não relacionado ao fato dele ter sido um inovador de nossa imprensa, o que é incontestável, mas localizado precisamente no modo como se dá a configuração dos gêneros em sua obra jornalística. Como se verá, não vejo pertinência na afirmação de que João do Rio renovou a imprensa porque misturou gêneros jornalísticos, rompendo paradigmas estabelecidos.

Pretendo aqui demonstrar - ou simplesmente sugerir, dados os limites de um artigo - que o modo como João do Rio (ou Paulo Barreto, seu verdadeiro nome, nascido em 1881 e morto em 1921) desenvolveu sua relação com os gêneros só pode ser rigorosamente compreendido quando se leva em conta, mesmo que rápida e subjacentemente, o contexto peculiar da imprensa jornalística brasileira em que sua obra se desenvolveu. Ou seja: a configuração dos gêneros jornalísticos da época de João do Rio é sensivelmente distinta do jornalismo com o qual nos habituamos, o qual traz as marcas das mudanças operadas somente a partir da segunda metade do século $X X$, isto é, aproximadamente 30 anos depois da morte de Paulo Barreto. Infelizmente, parece-me que é com essa perspectiva, a do padrão jornalístico do nosso tempo, que parte o olhar "atualizado" e, portanto, descontextualizado, em direção aos textos de João do Rio para enxergar neles uma mistura de gêneros. Acredito que muito da riqueza da obra de Paulo Barreto advém da convivência franca entre configurações textuais diversas, em uma verdadeira simbiose, sem que houvesse a exigência da demarcação rigorosa entre os gêneros. Assim, João do Rio foi repórter, cronista e contista, tudo de uma vez; sem deixar de ser também romancista e colunista social. Ressalto, pois, que um traço fundamental de sua obra deve ser identificado exatamente nessa pluralidade discursiva, pluralidade que é marca de uma 
incorporação eufórica de gêneros jornalísticos europeus pela imprensa brasileira em um momento de afirmação de sua feição industrial e comercial. Começo por aí.

\section{Produtos de um novo tempo}

O jornalismo brasileiro como atividade empresarial e profissional é acontecimento tardio. Se lembrarmos que nos Estados Unidos o jornalismo como negócio existe desde a década de 1830, salta à vista o contraste da constatação de que somente por volta de 1890 surgem no Brasil casas de imprensa que imprimem feição comercial e empresarial à atividade de produzir folhas noticiosas. E esse caráter de negócio associado ao jornalismo brasileiro deveu-se - ou esteve integrado - às transformações ocorridas na capital da República, o Rio de Janeiro, no bojo de um projeto de captação de capital estrangeiro, cujo aspecto mais aparente foi o processo de súbita urbanização da cidade do Rio, iniciada no governo de Rodrigues Alves, bem no nascedouro do século XX.

Chamamos de folhas noticiosas aos jornais que se modernizam nessa fase da imprensa brasileira, a de início de sua atividade eminentemente comercial, com a transformação de jornais que já existiam desde o início do século XIX, tais como A Gazeta de Notícias e O Jornal do Comércio, porque se nota aí uma decisiva alteração no modo do fazer jornalístico localizado exatamente na configuração de seus gêneros.

Assistia-se ao sepultamento das esclerosadas folhas do velho jornalismo do tempo da Monarquia, as quais, segundo o delicioso testemunho de Luiz Edmundo (1938), possuíam paginação sem movimento ou graça, um alinhamento monótono de colunas, desconheciam manchetes e outros procedimentos jornalísticos, isso quando não traziam um soneto na primeira página dedicado ao próprio diretor do jornal. Tratava-se também da prevalência de um jornalismo de doutrinação política, em que o velho artigo de fundo comparecia, com ares de austeridade e imponência.

No lugar disso, o advento de um jornalismo de caráter comercial significará dinamismo e captação do interesse das massas urbanas. No momento em que o Rio de Janeiro está decalcando Paris, com a grande remodelação urbana operada pelo prefeito Pereira Passos no início do século XX - o que permitirá, por exemplo, que as moças desfilem suas toilettes por grandes avenidas, sob o calor de um trópico nada parisiense - o jornalismo passa a tornar-se também um item de consumo para um público urbano que busca ajustar-se ao figurino civilizatório da modernidade. Fundamentalmente, a noção de ser a notícia o valor maior da atividade jornalística está no bojo dessas transformações. Que não se perca o que sugere a palavra valor. A notícia de fato passará a adquirir, aos poucos, a noção de produto comercial, em meio a tantos outros, na dinâmica da circulação de bens de consumo urbanos. E, como produto, es- tará cada vez mais destinada a incitar a curiosidade do público e ao mesmo tempo aplacá-la, trazendo "satisfação" a seus clientes, os leitores do jornal diário. Disputará a atenção do leitor com outros gêneros jornalísticos: a entrevista, a crônica, a coluna de variedades etc. Tais são os produtos de um novo tempo jornalístico. No lugar de doutrinação, entretenimento e informação.

Diante de tal panorama é, pois, perfeitamente compreensível que o componente noticioso, o registro do acontecimento, se amplifique e se enriqueça. Assim, o gênero noticioso em sentido estrito, o breve registro factual, o relato quase telegráfico, o mero anúncio do acontecido, parece ceder algum espaço para uma forma mais atraente de notícia, pois dinamizada em atributos discursivos bastante convidativos: a reportagem.

\section{Tensões e ambigüidades: 0 escritor e 0 jornalista}

Sendo uma modalidade noticiosa, a reportagem encontrará no trabalho de João do Rio, pseudônimo que Paulo Barreto passa a utilizar a partir de 1903, quando já atuava na Gazeta de Notícias, a maior expressão desse jornalismo novo. Vista em perspectiva, a imagem de João do Rio é a de quem compreendeu e assimilou os novos tempos da imprensa jornalística no Brasil, deslocando a imagem do escritor para as demandas que se apresentavam naquele contexto. Com ele, o escritor veste o figurino do jornalista e, mais particularmente, do repórter.

Embora consideremos a pluralidade de marcas dos gêneros, destaco agora a reportagem. É de fato com João do Rio que se desenvolve, no Brasil, a reportagem em sentido pleno, ou seja, a que faz da atuação do repórter em seu ofício de ir à cata da informação a condição fundamental sem a qual não se elabora a informação jornalística. Pode-se dizer que com ele enfatiza-se o próprio jornalista, ou seja, o profissional a partir de cuja ação se desenvolve o acontecimento noticioso. E os textos de João do Rio são reportagens em que a própria ação de reportar é evidenciada. Se pode sempre haver dúvida de que teria sido ele o primeiro repórter brasileiro, não se pode negar que seus textos são os primeiros a demonstrar a consciência sobre o ofício do jornalista, na revelação do comportamento do repórter.

No entanto, é necessário equacionar um problema que parece ter sempre acompanhado a recepção crítica da obra de João do Rio em momentos distintos. É possível identificar uma tensão entre tendências opostas que pode ser estabelecida em pares de dicotomias: se por um lado ele é visto como aquele que consagrou a imagem do jornalista como um profissional, por outro lado paira sobre ele a imagem de um dândi e, nesse sentido, do anti-profissional, o eterno diletante; se por um lado sua produção em jornais é vista como reportagem, por outro se atribui a ela a classificação de crônica, o que a associa à realização literária: se por um lado dá-se credibilidade e acre- 
dita-se na veracidade de suas reportagens, afirmando-se serem elas fruto de apuração rigorosa de jornalismo moderno, por outro já se considerou que possuem muito de ficção, produtos da fantasia e da imaginação; se por um lado ele é o jornalista, por outro é o escritor ficcionista. Veja-se, por exemplo, como Agripino Grieco, na Evolução da Prosa Brasileira, de 1933, aponta para o lado ficcional em João do Rio presente na série de reportagens de As Religiões do Rio:

"O autor, para se tornar interessante, teve de inventar muita coisa, e certos diabololismos, certas missas negras do in-folio, denunciam o leitor do mago Papus e do Huysmans do Là-bas". (GRIECO, 1933, p. 176).

Já para um biógrafo de João do Rio, João Carlos Rodrigues, veracidade não falta à série de reportagens: "Suas informações são verídicas, e mesmo os cânticos em ioruba (nagô) sobrevivem até os dias de hoje". (RODRIGUES, 1996, p. 50)

Um estado de tensão parece configura-se no confronto entre a imagem de jornalista e a do escritor literário, o repórter em conflito com o ficcionista. Diante disso, acredito que se deve marcar aqui a ênfase em uma operação: o que se anunciou como dicotomia deve, na verdade, transformar-se em ambigüidade. Ou seja: no lugar de se evidenciarem embates e oposições, creio que é necessário valorizar a noção de uma convivência simultânea e inseparável de aspectos. A idéia de ambigüidade em João do Rio parece-me válida e preciosa exatamente porque reconhece uma escrita em que os termos do factual e do ficcional não se separam ou se excluem; em que o jornalístico, assumindo já o padrão moderno que se baseia no trabalho de apuração dos acontecimentos, ao mesmo tempo convive com procedimentos próprios da representação literário-ficcional.

Acredito que tal ambigüidade - ou ambivalência - em nada desfigura a importância de João do Rio para o desenvolvimento do jornalismo e da reportagem no Brasil. Ao contrário, revela ter sido ele homem de seu tempo. Um tempo de trânsito de gêneros e de ajustes, um momento em que o texto jornalístico iniciava sua aventura de seduzir o leitor - em que ainda se estava muito distante da padronização estilística que expulsaria a literatura dos atributos da reportagem, o que no Brasil ocorreria a partir da década de 1950 - uma fase, pois, em que é perfeitamente natural que recursos de representação ficcional sejam evocados, eis o vislumbre do contexto peculiar em que se situou João do Rio, eis o vislumbre das condições peculiares em que sua obra se desenvolveu.

Tal caráter de ambigüidade e ambivalência impregna as principais obras de João do Rio: As Religiões do Rio, de 1904, A Alma Encantadora das Ruas, de
1908, Cinematógrafo, de 1909, Vida Vertiginosa, de 1911, Os Dias Passam, de 1912. Curiosamente, se nessas obras - algumas das mais representativas e que enfeixam suas grandes crônicas-reportagens há o comparecimento de atributos de ficção literária, naquelas em que salta à vista a dedicação à literatura propriamente dita, como Dentro da Noite, de 1910, ou Correspondência de uma Estação de Cura, de 1918, recursos de jornalismo são também convocados. Aliás, a importância estritamente literária de João do Rio nem sempre foi reconhecida. Parece ter havido sempre um desconforto em acondicioná-lo em um manual de história da literatura brasileira. Alguns críticos enfatizaram em sua produção a presença de uma dicção de frivolidade e de um repertório de clichês típicos da Belle Époque, ajustados à imagem de dândi que envolvia a vida do jornalistaescritor. Outros pouco disfarçaram um juízo desfavorável, como é o caso de Lúcia Miguel Pereira (1988). De um modo geral, permanece de fora dos manuais de literatura mais recentes e é praticamente desprezado pelos estudos literários de nossos cursos de letras. Já os pesquisadores da "nova história" têm nele um manancial extraordinário para explorar aspectos fascinantes de nossa "vida privada".

\section{0 registro do efêmero}

Se há um aspecto essencial na obra de João do Rio que a vincula fundamentalmente à vivência jornalística é a marca da transitoriedade do tempo. Muito da valorização dessa obra deveu-se ao fato de ser ela um registro das transformações do início do século XX operadas na vida urbana do Rio de Janeiro. "O Rio Civiliza-se", frase daquele momento, funciona como emblema que sintetiza a arrojada transformação urbana operada pelas grandes obras do prefeito Pereira Passos. Tratava-se de transformar a feição acanhada de uma cidade colonial, com seus casebres e cortiços, em metrópole moderna, uma espécie de Paris dos trópicos, cosmópolis da Belle Époque brasileira. Tendo sido João do Rio uma espécie de documentarista das transformações do plano aparente da cidade, será ele também arguto observador das modificações que se estariam processando no âmbito dos costumes, do comportamento, dos hábitos das criaturas daquela cosmópolis.

Assim, vai ele acompanhar os novos "vícios" que se incorporavam, as chegadas extravagâncias mundanas de Paris, o chic dos novos modos de viver, de se vestir, de flertar, de figurar nas altas rodas sociais, enquanto documenta a decadência das velhas profissões e seus tipos sociais, que tombavam como os antigos casarões coloniais, com a abertura de um boulevard ou de um cinematógrafo. Veja-se um exemplo em Vida Vertiginosa:

Antigamente tremeríamos de horror. Hoje, estas duas pequenas são quase nada de grave. Semivirgens? Contaminadas de flirt? Sei lá. É 
preciso conhecer o Rio atual para apanhar o pavor imenso do que poderíamos denominar a prostituição infantil. (RIO, 1911, p. 91)

É preciso, no entanto, perceber como reage o narrador que há nos textos de João do Rio diante desse espaço que no tempo se transfigura. Há, notoriamente, uma posição ambígua: o narrador encantase, entusiasma-se, diverte-se com as modificações e busca mesmo integrar-se aos novos costumes da cidade, a seu novo cenário urbano, aos seus novos veículos de transporte, à nova feição das ruas; ao lado disso e às vezes ao mesmo tempo, esse narrador assusta-se com as transformações, sofre com a transitoriedade, é saudosista. Assim é ele em "A Era do Automóvel", também de Vida Vertiginosa. Há um misto de pasmo e deslumbramento: "O automóvel ritmiza a vida vertiginosa, a ânsia das velocidades, o desvario de chegar ao fim, os nossos sentimentos de moral, de estética, de prazer, de economia, de amor." (RIO, 1911, p. 4).

Mas a ironia vem condenar o espantoso veículo. A era do automóvel trouxe para o cronista-repórter uma nova linguagem. Hoje, nós ouvimos diálogos bizarros:

- Foste ao ACB? - Iéss.

- Marca da fábrica? - FIAT 60 HP.

- Tenho que escrever no ACOTUK.

(RIO, 1911, p. 5).

Assim, o narrador toma o automóvel como símbolo dos novos tempos, nos quais a velocidade atingiria as próprias formas de expressão escrita:

Assim como encurta tempo e distância no espaço, o automóvel encurta tempo e papel na escrita. Encurta mesmo as palavras inúteis e a tagarelice. O monossílabo na carreira é a opinião do homem novo. A literatura é ócio, o discurso é impossível. (RIO, 1911, p. 6).

A presença da transitoriedade, a marcação do efêmero nas crônicas-reportagens de João do Rio encontra-se num caminho de dupla via. Por um lado o olhar tenta fixar o passado e parece lamentar a perda do tempo antigo, a velha cidade do Rio, daí o empenho do repórter-cronista em registrar dados da cidade antiga, marcas de sua velha fisionomia: tílburis, ruas estreitas, costumes, vícios. Por outro lado, parece haver a necessidade de fixar exatamente a retificação do passado e o despontar daquilo que o nega, historiando a transformação irremediável da fisionomia dos tempos.

\section{0 espetáculo mundano}

Aliando-se a essa preocupação com o registro do transitório, em uma atitude que traz as marcas do gênero crônica em seu sentido primordial, encontra- se nos textos de João do Rio a presença dos aspectos da vida mundana: descrição dos elementos da dimensão material, apresentação dos modos concretos da atividade social e econômica da cidade, explicitação dos hábitos, costumes e "vícios" de seus habitantes, demonstração das maneiras do comportamento das massas urbanas. Assim, ler João do Rio não deixa de ser uma experiência em que o leitor "prova" de um cardápio de elementos que compõem o cenário da época e o espaço de uma cidade: moda, gastronomia, religião, meios de transporte, arquitetura, tecnologia, esporte, dança, lazer, vícios e prazeres (cigarros, bebidas, ópio), decoração, paisagismo, urbanismo etc.

O repórter-cronista nada quer deixar passar sem seu registro. Em "Modern Girls", de Vida Vertiginosa, observa, por exemplo, o quesito da moda. Já em "Presepes" de A Alma Encantadora das Ruas, apresenta um "quadro" em que são dispostos objetos que compõem uma sala, ao mesmo tempo em que são descritos movimentos de capoeiristas.

Dentro move-se, numa alegria carnavalesca, o bando de capoeiras perigosos da rua da Conceição, de S. Jorge e da Saúde. A sala tem cadeiras em roda, ornamentadas de metim vermelho, cortinas de renda com laçarotes estridentes. As matronas espapaçam-se nas cadeiras, suando, e, em movimentos nervosos, agitam-se à sua vista mulatinhas de saiote vermelho, brutamontes de sapatos de entrada baixa e calção de fantasia de velho e de rei dos diabos. Há um cheiro impertinente de suor e de éter floral. (RIO, 1908, p. 126-127).

É preciso, entretanto, ampliar o conceito de mundanismo. O que é ser um repórter mundano além de possuir certa obsessão pelo prosaísmo da vida cotidiana? Muito já se disse a respeito de uma postura que João do Rio transmitiu para o jornalismo brasileiro: a de quem não fica mais no espaço da redação de um jornal à espera do fato (ou do "foca"), aguardando material para as reportagens, mas que sai às ruas, passeia por bairros pobres, freqüenta a alta sociedade, adentra-se nas igrejas e nos terreiros de macumba (como no caso de As Religiões do Rio). Todavia, o mundanismo implica algo mais: libertinagem, desregramento. O repórter mundano é aquele "sujeito do mundo", que está caminhando pelas ruas e becos, que é um autêntico flâneur, alguém com ares de desocupado, que freqüenta a society e também pode envolver-se em uma perigosa aventura descendo aos infernos do submundo. Em "Os Livres Acampamentos da Miséria", de Vida Vertiginosa, ele se lança à perigosa aventura de subir o morro e nesse espaço - alto e baixo, simultaneamente - participa de uma seresta, integra-se a um grupo de malandros, envolve-se com o ambiente de libertinagem, de indolência. Ao chegar ao alto do morro, ele 
tem a cidade sob seus olhos e, contemplando-a, constata a distância entre dois mundos e o sentido da aventura que vivenciou:

E quando de novo cheguei ao alto do morro, dando outra vez com os olhos na cidade, que embaixo dormia iluminada, imaginei chegar de uma longa viagem a um outro ponto da terra, de uma corrida pelo arraial da sordidez alegre, pelo horror inconsciente da miséria cantadeira, com a visão dos casinhotos e das caras daquele povo vigoroso, refestelado na indigência em vez de trabalhar, conseguindo bem no centro de uma grande cidade a construção inédita de um acampamento de indolência, livre de todas as leis. (RIO, 1911, p. 152)

O repórter-cronista vai ao campo degradado dos acontecimentos e de lá retorna, restituindo-se para o mundo "alto" da cidade. Ele sabe dos grandes perigos da aventura e precisa salvar-se. Para o leitor, a narrativa de "Os Livres Acampamentos da Miséria" passa a ser a de um personagem-jornalista com atitudes de flâneur que se arrisca em busca de assunto para seu texto. No final, ele sai do inferno em que se metera, deixa o morro, o escuro da noite, escapa liricamente para encontrar na cidade o amanhecer:

De repente, lembrei-me de que a varíola cairia ali ferozmente, que talvez eu tivesse passado pela toca de variolosos. Então, apressei o passo de todo. Vinham a empalidecer na pérola da madrugada as estrelas palpitantes e canoramente galos cantavam por trás das ervas altas, nos quintais vizinhos. (RIO, 1911, p. 152).

\section{Informação e ficção}

Há uma ambigüidade bastante valiosa em João do Rio: a convivência do flâneur com o jornalista profissional. De fato, ele condensa dois comportamentos, aparentemente inconciliáveis. Há muito de postura aristocrata no flâneur, o dândi despreocupado que vagueia pelas ruas, aberto às contingências do acaso, cujo melhor exemplo está em A Alma Encantadora das Ruas. Mas, ao mesmo tempo, ele é o jornalista, alguém investido de uma atitude profissional, que realiza entrevistas e apura os fatos. É, pois, válido lançar uma curiosa designação para João do Rio: a de repórter-flâneur. Sintomaticamente, tal postura ambígua sinaliza o momento de transição vivido pela imprensa brasileira no início do século $X X$, representada pela convivência de um amadorismo persistente, presente na atitude do flâneur, com o arrojo do profissionalismo exigido pelas demandas empresariais que se apresentavam, presente na postura do repórter.

Seja como for, se esse repórter-flâneur é alguém que às vezes "desce aos infernos" e dele se salva, se ele se desloca no espaço da cidade, se freqüenta tanto ambientes perigosos quanto os da society, esse enfrentamento dos perigos e esse acesso a ambientes sociais requintados fazem-se também em nome da informação. Entretanto, é necessário enfatizar que a informação não se circunscreve à mera enunciação de um acontecimento. Em vez disso, há um processo narrativo que atualiza os acontecimentos, presentificando-os, por assim dizer, fazendo com que o leitor acompanhe o desenrolar da ação como se fosse uma testemunha.

Ótima demonstração do forte caráter informativo na obra de João do Rio está em "A Fome Negra", de A Alma Encantadora das Ruas, crônica-reportagem sobre trabalhadores na Ilha da Conceição, depósito de manganês e carvão. $\mathrm{O}$ texto chama a atenção pela crueza da focalização, que se faz inicialmente pela apreensão do todo, observação do conjunto, a coletividade de trabalhadores anônimos. Como se pode notar, o lirismo cede um pouco a vez para a busca do efeito de objetividade jornalística:

Logo depois do café, os pobres seres saem do barraco e vão para a parte norte da ilha, onde a pedreira refulge. Há grandes pilhas de bloco de manganês e montes de piquiri em pó, em lascas finas. No solo, coberto de uma poeira negra com reflexos de bronze, há rails para conduzir os vagonetes do minério até o lugar da descarga. O manganês, que a Inglaterra cada vez mais compra do Brasil, vem de Minas até a Marítima em estrada de ferro; daí é conduzido em batelões e saveiros até as Ilhas Bárbaras e da Conceição, onde fica em depósito. (RIO, 1908, p. 176).

Este trecho se assemelha à prosa de ficção realista-naturalista - ou aparentada dela - cujas narrativas têm início com a apreensão da atividade coletiva. Penso em alguns exemplos célebres: Germinal de Émile Zola, Mãe de Máximo Gorki, O Cortiço de Aluísio Azevedo. E este parentesco com a ficção literária não implica o afastamento de seu caráter informativo: há toda uma preocupação com os dados concretos, verificáveis, apurados da realidade empírica. É que, nesse caso, se é possível aproximar a crônica-reportagem de João do Rio de uma dicção naturalista é porque, como bem se sabe, o naturalismo tem como um dos seus pressupostos fundamentais a verificação dos dados da realidade sensível. Com Zola, a literatura assumiu ma espécie de compromisso de destituição do comportamento inventivo da prosa literária. O escritor deveria ser um observador rigoroso dos dados oferecidos pelo real. $\mathrm{O}$ que houvesse de material ficcional no plano do enredo deveria estar apoiado nos poderes de observação. A referência a Zola é aqui imprudente, pois pode incitar uma discussão bastante ampla sobre as relações entre a prosa jornalística e literária que ex- 
trapola os limites deste texto; sobre o modo como teria havido uma reciprocidade de influência ou trânsito de "poéticas"; fazendo pensar, por exemplo, no modo como o jornalismo do século XX foi se tornando cada vez mais "realista-naturalista" ao incorporar um efeito de parcialidade e aparar as arestas da subjetividade exaltada dos periódicos do século XIX.

De qualquer modo, as marcas inequívocas de prosa naturalista nos textos de João do Rio parecem denunciar a influência do movimento francês no período de iniciação de Paulo Barreto. Dito isso, volto à "fome negra" para destacar que no texto há uma expressão que enfatiza a habitualidade, a repetição das ações, do movimento geral que envolve o vapor, o saveiro, os trabalhadores. Pouco a pouco, no entanto, o texto vai abandonando a apreensão do coletivo para encontrar um enfoque mais individualizado por meio de personagens e de uma situação determinada, reduzindo o campo de ação, indo ao encontro de um esquema narrativo elementar, com desenvolvimento, clímax, desenlace. Ou seja, a reportagem - que também apresenta traços de crônica - vai encontrando os contornos do conto: "O trabalho recomeçou. O Corrêa, cozido ao sol, bamboleava a perna, feliz. Como a vida é banal. Esse Corrêa é um tipo que existe desde que na sociedade organizada há o intermediário entre o patrão e o servo". (RIO, 1908, p. 180)

Torna-se compatível, no fim das contas, o caráter informativo com o traço ficcional. Com efeito, o ficcional em João do Rio está no limite dos componentes da chamada referencialidade jornalística, constituindo uma região de fronteira, um espaço cujos domínios são indefinidos. Acredito que é irrelevante investigar - se fosse possível fazê-lo - o quanto há de invenção ou de registro factual nas crônicas e reportagens de João do Rio. Sua prosa não é mero registro de fatos e de contingências mundanas rigorosamente observadas. Há um efeito de intervenção subjetiva, há uma expressão inequivocamente lírica e, ainda, um modo de narrar que incorpora e revela traços marcantes de fabulação.

Afonso Lopes de Almeida, citado por Cremilda Medina (1978, p. 58), destaca que uma das principais inovações de João do Rio foi transformar a crônica em reportagem na ação de tirar o jornalista do espaço da redação e levá-lo ao locus dos acontecimentos. Penso, no entanto, que a importância da menção deve ser valorizada com a observação de que se trata de uma marca fundamental no interior da configuração narrativa. Ou seja, esse cronista (e repórter) que vai ao palco dos acontecimentos como um flâneur é, na verdade, uma entidade da narrativa. Trata-se de uma personagem, se quisermos usar o termo sem atribuir-lhe a necessidade de contornos psicológicos e físicos definidos. Sendo narrador, ele se comporta, ao mesmo tempo, como representação ficcional.
Acredito, pois, que é necessário enfatizar em João do Rio a aproximação entre literatura e imprensa por meio da identificação de uma questão situada precisamente no comportamento do narrador. Mais precisamente, a postura do narrador é a de um personagem de ficção investido da ação própria do profissional da imprensa, repórter ou cronista; e, especialmente, de um ente que se movimenta no espaço urbano e vive "de dentro" a aventura da própria reportagem ou crônica a ser escrita. O repórtercronista assume no texto o estatuto de personagem de ficção. Mais: em muitos casos, as narrativas processarão as aventuras de um personagem narradorrepórter na aventura de colher o material jornalístico. Com isso, não há um efeito discursivo de separação entre o narrador-personagem e o fato narrado.

A herança de João do Rio faz-se sentir em alguns escritores-cronistas praticamente esquecidos: Benjamin Costallat, Sylvio Floreal, João de Minas, Théo Filho. Provocativamente, poderia também aproximá-lo de um escritor - esse lembrado - situado em contexto bastante distinto de Paulo Barreto, numa espécie de "aproximação invertida": João Antônio. Ambos, repórteres-ficcionistas, flagram o cotidiano das ruas; ambos configuram narrativas de trânsito com a vida prosaica. Em ambos, de certo modo a narrativa configura o ato de percorrer e (re) conhecer a cidade. E a narração é a enunciação do ato de transitar. Há, é claro, algo que os separa drasticamente: João do Rio é o cronista-repórter afeito ao requinte mundano, ao esnobismo da Belle Époque. João Antônio, bem ao contrário, é o contemplador das misérias da urbs caótica, da metrópole degradada.

De modo geral, fica um dos elementos definidores da reportagem de João do Rio: há o ficcionista; no repórter, um personagem. $\mathrm{O}$ autor dinamizou a atividade jornalística, renovou-a; lançou o repórter na rua, lançou-o à vida vertiginosa e encantadora da cidade. Desapegado dos limites da sala de redação, vivenciou uma experiência textual também sem limites, assumindo o contexto de dinamismo dos novos tempos, com a convivência ambígua entre gêneros e fazendo também do jornalismo expressão literária.

\section{Conclusão: 0 que não é jornal velho}

Procurei chamar a atenção para o perigo de se lançar um olhar dirigido ao tempo de João do Rio a partir da perspectiva do nosso. Tal ressalva foi fundamental para que eu pudesse reconhecer alguns aspectos importantes da configuração de textos jornalísticos de João do Rio, enfatizando a convivência entre gêneros, reportagem, crônica, conto, convivência bastante natural no contexto de nossa Belle Époque. De fato, o tempo de Paulo Barreto não foi marcado por uma delimitação rigorosa entre os gêneros jornalísticos, algo que se vai desenvolver no Brasil a partir da década de 1950, embora se reconheça o 
pioneirismo do Diário Carioca na incorporação do padrão jornalístico norte-americano, já em 1943. (SILVA, 1990)

Penso que não se pode afirmar que a obra de João do Rio desobstruiu fronteiras rigorosas entre gêneros jornalísticos, pois elas não existiam. Não com as exigências prescritivas que vigorariam depois, estabelecidas, inclusive, em manuais de redação. Se ele retificou um padrão jornalístico anterior, o fez no interior de um processo mais amplo, o de uma transformação em curso encampada por jornais do Rio de Janeiro, os quais passavam a adotar uma feição empresarial e comercial para a atividade jornalística, em franca sintonia com as demandas da modernidade. Tratou-se de uma fase de incorporação de gêneros praticados na Europa - reportagem, crônica, colunismo, caricatura - e procedimentos como manchete e subtítulos. Tais recursos visavam a imprimir dinamismo, buscavam seduzir e interessar um contingente populacional urbano que se esforçava para se ajustar ao figurino da modernidade. João do Rio entrou em perfeita sintonia com esse contexto, produzindo uma obra jornalística afeita às demandas comerciais que se anunciavam, fornecendo ao público apelos de curiosidade em reportagens de feição narrativa e com ingredientes típicos de ficção.

É preciso desmontar a insatisfatória postura que busca rotular a obra de João do Rio. Alguns críticos o chamaram apenas de cronista, outros, repórter. Outros nem mencionaram a palavra jornalista. Seja como for, tais veredictos são sinais de uma postura classificatória que segmenta os gêneros, perigosa e inócua no caso de Paulo Barreto. É necessário, ao contrário, aceitar o vasto território de ambigüidade e pluralismo que a impregna.

Chegado a esse ponto, lanço uma afirmação que aparentemente contradiz o que defendi até aqui: é necessária uma aproximação com o tempo de João do Rio. É preciso trazê-lo para o nosso tempo, em atitude reflexiva e questionadora. A contradição de fato é aparente, pois não proponho olhar para o contexto jornalístico de Paulo Barreto segundo a perspectiva do padrão jornalístico de nossa época. É necessária, ao contrário, uma operação de ajuste de foco, de observação rigorosa das condições de produção jornalísticas peculiares de seu tempo, para que, a partir daí, o legado de Paulo Barreto seja melhor assimilado. Para que, inclusive, não seja mero legado, objeto fóssil, documento ou "memória".

Cada vez mais se sabe que o nome de João do Rio é indispensável para a compreensão da história de nosso jornalismo. Mas, ao lado da compreensão histórica, penso que sua obra é fundamental para a reflexão sobre a natureza e a linguagem jornalística e para um questionamento bastante atual e de certo modo permanente. Trata-se de uma atitude reflexiva direcionada às formas de expressão do jornalismo e à sua própria natureza. E as características dessa obra, com seus traços peculiares, podem ense- jar uma discussão sobre o nosso modo contemporâneo de fazer jornalismo, promovendo, indiretamente, o questionamento da padronização da textualidade jornalística e o cotidiano "burocrático" que parece ter impregnado o ambiente de nossas salas de redação. Ou seja, tudo o que a reportagem em João do Rio não foi. Em um tempo de extrema mecanização do ofício jornalístico, em uma fase em que o repórter parece ficar cada vez mais estático - aliás, uma época em que estão desaparecendo as funções especializadas de repórter, editor, redator, com o movimento de enxugamento das empresas jornalísticas - e o jornalista parece estar cada vez mais amarrado à sala de redação, sem contato direto com o cotidiano a ser por ele reportado, o nome de João do Rio pode soar como um exemplo radical de contraste.

Passados mais de cem anos, os textos de João do Rio permanecem como uma das maiores realizações de textualidade jornalística de nosso país. Trata-se de um material fascinante, rico em potencialidades expressivas que, exatamente por isso mesmo, se renova a cada leitura. Mas, curiosamente, essa textualidade jornalístico-literária, inapelavelmente impregnada das marcas de sua época, deve ser convocada a participar dos questionamentos, inquietações e perplexidades próprias de nosso tempo, assumindo novas e instigantes configurações. mFamecos

\section{REFERÊNCIAS}

EDMUNDO, Luiz. O Rio de Janeiro de meu tempo. Rio de Janeiro: Companhia Editora Nacional, 1938.

GRIECO, Agripino. Evolução da prosa brasileira. Rio de janeiro: Ariel, 1933.

MEDINA, Cremilda. Notícia, um produto à venda: jornalismo na sociedade urbana e industrial. 2. ed. São Paulo: Summus, 1988.

PEREIRA, Lúcia Miguel. História da literatura brasileira: prosa de ficção: de 1870 a 1920. Belo Horizonte: Itatiaia; São Paulo: USP, 1988.

RIO, João do. A alma encantadora das ruas. Paris: H. Garnier, 1908.

Vida vertiginosa. Rio de Janeiro: Garnier, 1911.

RODRIGUES, João Carlos. João do Rio: uma biografia. Rio de Janeiro: Topbooks, 1996.
SILVA, Carlos Eduardo Lins da. O adiantado da hora: a influência americana sobre o jornalismo brasileiro. São Paulo: Summus, 1990. 